\title{
Asymmetric responses to simulated global warming by populations of Colobanthus quitensis along a latitudinal gradient
}

\author{
Ian S. Acuña-Rodríguez ${ }^{1}{ }^{\text {, }}$ Cristian Torres-Díaz ${ }^{2}{ }^{\text {, }}$ Rasme Hereme ${ }^{1}{ }$, Marco A. Molina-Montenegro ${ }^{\text {Corresp. } 1,3,4}$ \\ ${ }^{1}$ Centro de Ecología Molecular y Aplicaciones Evolutivas en Agroecosistemas (CEM), Instituto de Ciencias Biológicas, Universidad de Talca, Talca, Chile \\ 2 Laboratorio de Genómica y Biodiversidad (LGB), Departamento de Ciencias Básicas, Universidad del Bío-Bío, Chillan, Chile \\ 3 Centro de Estudios Avanzados en Zonas Áridas (CEAZA), Facultad de Ciencias del Mar, Universidad Católica del Norte, Coquimbo, Chile \\ 4 Research Program "Adaptation of Agriculture to Climate Change" PIEI A2C2, Universidad de Talca, Talca, Chile
}

Corresponding Author: Marco A. Molina-Montenegro

Email address: marco.molina@utalca.cl

The increase in temperature as consequence of the recent global warming has been reported to generate new ice-free areas in the Antarctic continent, facilitating the colonization and spread of plant populations. Consequently, Antarctic vascular plants have been observed extending their southern distribution. But, as the environmental conditions toward southern localities become progressively more departed from the species' physiological optimum, the ecophysiological responses and survival to the expected global warming could be reduced. However, if processes of local adaptation are the main cause of the observed southern expansion, those populations could appear constrained to respond positively to the expected global warming. Using individuals from the southern tip of South America, the South Shetland Islands and the Antarctic Peninsula, we assess with a long term experiment ( 3 years) under controlled conditions if the responsiveness of Colobanthus quitensis populations to the expected global warming, is related with their different foliar traits and photoprotective mechanisms along the latitudinal gradient. In addition, we tested if the release of the stress condition by the global warming in these cold environments increases the ecophysiological performance. For this, we describe the latitudinal pattern of net photosynthetic capacity, biomass accumulation, and number of flowers under current and future temperatures respective to each site of origin after three growing seasons. Overall, was found a clinal trend was found in the foliar traits and photoprotective mechanisms in the evaluated C. quitensis populations. On the other hand, an asymmetric response to warming was observed for southern populations in all ecophysiological traits evaluated, suggesting that low temperature is limiting the performance of $\mathrm{C}$. quitensis populations. Our results suggest that under a global warming scenario, plant populations that inhabiting cold zones at high latitudes could increase in their ecophysiological performance, enhancing the size of populations or their spread. 


\section{Asymmetric responses to simulated global warming by populations of}

\section{Colobanthus quitensis along a latitudinal gradient}

3

4 Ian S. Acuña-Rodríguez ${ }^{1}$, Cristian Torres-Díaz ${ }^{2}$, Rasme Hereme ${ }^{1}$ and Marco A. Molina-Montenegro ${ }^{1,3,4^{*}}$

5

$6{ }^{1}$ Centro de Ecología Molecular y Aplicaciones Evolutivas en Agroecosistemas (CEM), Instituto de

7 Ciencias Biológicas, Universidad de Talca, Avda Lircay s/n, Talca, Chile.

8 22Laboratorio de Genómica y Biodiversidad (LGB), Departamento de Ciencias Básicas, Universidad del

9 Bío-Bío, Chillán, Chile.

$10{ }^{3}$ Centro de Estudios Avanzados en Zonas Áridas (CEAZA), Facultad de Ciencias del Mar, Universidad 11 Católica del Norte, Coquimbo, Chile.

12 "Research Program "Adaptation of Agriculture to Climate Change" PIEI A2C2, Universidad de Talca, 13 Talca, Chile.

18 *Author for correspondence: Marco A. Molina-Montenegro; Avenida Lircay s/n, Talca, Chile; E-mail:

19 marco.molina@utalca.cl 


\section{ABSTRACT}

22 The increase in temperature as consequence of the recent global warming has been reported to generate

23 new ice-free areas in the Antarctic continent, facilitating the colonization and spread of plant populations.

24 Consequently, Antarctic vascular plants have been observed extending their southern distribution. But, as

25 the environmental conditions toward southern localities become progressively more departed from the

26 species' physiological optimum, the ecophysiological responses and survival to the expected global

27 warming could be reduced. However, if processes of local adaptation are the main cause of the observed

28 southern expansion, those populations could appear constrained to respond positively to the expected

29 global warming. Using individuals from the southern tip of South America, the South Shetland Islands

30 and the Antarctic Peninsula, we assess with a long term experiment (3 years) under controlled conditions

31 if the responsiveness of Colobanthus quitensis populations to the expected global warming, is related with

32 their different foliar traits and photoprotective mechanisms along the latitudinal gradient. In addition, we

33 tested if the release of the stress condition by the global warming in these cold environments increases the

34 ecophysiological performance. For this, we describe the latitudinal pattern of net photosynthetic capacity,

35 biomass accumulation, and number of flowers under current and future temperatures respective to each

36 site of origin after three growing seasons. Overall, was found a clinal trend was found in the foliar traits

37 and photoprotective mechanisms in the evaluated $C$. quitensis populations. On the other hand, an asymmetric response to warming was observed for southern populations in all ecophysiological traits evaluated, suggesting that low temperature is limiting the performance of C. quitensis populations. Our results suggest that under a global warming scenario, plant populations that inhabiting cold zones at high latitudes could increase in their ecophysiological performance, enhancing the size of populations or their 42 spread. 


\section{INTRODUCTION}

The Antarctic continent is among the most stressful environments for plant life worldwide (Robinson, Wasley \& Tobin, 2003; Peck, Convey \& Barnes, 2006); establishment and survival is limited by conditions such as low temperatures, desiccation, wind abrasion, high radiation and low water and nutrient availability (Alberdi et al., 2002; Robinson, Wasley \& Tobin, 2003; Wasley et al., 2006; Convey, 2011). Although it was recently indicated that warming has stopped in Antarctica (Turner et al. 2016), over the last few 50 years the mean annual temperature of the Antarctic Peninsula increased by almost 3 ${ }^{\circ} \mathrm{C}$ (Vaughan et al., 2003; Turner et al., 2014). Although global warming is a major threat for biodiversity worldwide, the Antarctic region is particularly sensitive to small increases in temperature, showing changes long before they can be seen elsewhere in the world (Walther et al., 2002; IPCC, 2014).

Only two vascular plants (Deschampsia antarctica and Colobanthus quitensis) have been able to establish and survive in Antarctica. Although both species are present in the same spatial range in Antarctica (from $62^{\circ} \mathrm{S}$ to $68^{\circ} \mathrm{S}$ ), C. quitensis is more restricted in its habitat distribution than $D$. antarctica. C. quitensis (Kunth) Barttl. (Caryophyllaceae), commonly known as the Antarctic pearlwort, is a small-sized cushion-like perennial herb, with self-compatible sexual reproduction (Kennedy, 1993; Convey, 1996). The Antarctic pearlwort has an extremely wide range of distribution spanning from Mexico $\left(17^{\circ} \mathrm{N}\right)$ to the southern Antarctic Peninsula (69 $\left.{ }^{\circ} \mathrm{S}\right)$ (Smith, 2003; Convey, 2012). Recent warming during the last five decades has produced new summer ice-free areas, which have provided suitable habitats for plant colonization (Convey et al., 2014; Cannone et al., 2016). Consequently, increases in both the size and number of $C$. quitensis and D. antarctica populations have been reported (e.g., Smith, 1994; Day et al., 1999; Torres-Mellado et al., 2011; Cannone et al., 2016), and southward population expansions can be projected for the next century. Although climate change is expected to have an overall positive impact on the growth, survival and fitness of C. quitensis (Convey, 2011; Day et al., 2009; Molina-Montenegro et al., 2012a; Torres-Díaz et al., 2016), the eco-physiological responses to the different components of climate change (e.g., warming) could differ among populations along the latitudinal gradient. 
In species with widespread distribution ranges, peripheral populations such as those of $C$. quitensis

72

from the Antarctic Peninsula (ca. $68^{\circ} \mathrm{S}$ ) are expected to depart more from the species' physiological optimum than their central or northern counterparts (Gaston, 2009; Sexton, Hangartner \& Hoffman, 2014). This prediction finds support in previous studies showing that $C$. quitensis is limited by abiotic conditions (e.g., low temperatures); this limitation is more evident in the southern populations of its range (Gianoli et al., 2004; Sierra-Almeida et al., 2007; Torres-Diaz et al., 2016). For instance, Sierra-Almeida et al. (2007) found significantly higher net photosynthesis rates in Antarctic (62 ${ }^{\circ} \mathrm{S}$, King George Islands) than in Andean $\left(33^{\circ} \mathrm{S}\right.$, La Parva) populations of C. quitensis at both low and high temperatures (4 and 15 ${ }^{\circ} \mathrm{C}$ ), suggesting that Antarctic populations of C. quitensis are physiologically adapted to colder habitats and that thermal stress release would produce increases in their performance. With respect to cold adaptation, Gianoli et al. (2004) found greater levels of freezing resistance after cold acclimation and shorter and wider leaves in Antarctic than Andean genotypes. The conjunction of high irradiance and low temperature may damage the photosynthetic apparatus, causing a reduction in photosynthesis known as photoinhibition (Demmig-Adams \& Adams, 1992). Bascuñan-Godoy et al. (2010) showed that foliar microstructures as well as high levels of the xanthophyll cycle pool helped to maintain high physiological performance in C. quitensis from an Antarctic population more than an Andean population under high radiation and low temperature conditions. Thus, differential responses in morphology and/or physiology can be expected among populations of $C$. quitensis along the latitudinal distribution gradient, based on the most recent global warming predictions and models (IPCC, 2014; Turner et al., 2014).

Since Antarctic fieldwork can be complex and logistically demanding, most of the experimental studies of global warming have been carried out under controlled laboratory conditions using present and future climate scenarios (Molina-Montenegro et al., 2016, but see: Day et al., 2008 and Day et al., 2009). Most studies assessing the effects of warming on different plant species along a latitudinal gradient use a constant rise in temperature for all origins, although warming is specific to every place (IPCC, 2014). Thus it is common to observe several studies assessing the effects of global warming on Antarctic plant species that have used only one temperature to represent the current conditions of the Antarctic ecosystem 
97 -Peninsula or Maritime Antarctica- as well as for the projected warming. But since a strong abiotic stress

98 increase is present along the latitudinal gradient from the South Shetland Islands to the Antarctic

99 Peninsula, it generates an important bias for the local conditions compared to the regional averages

100 (Vaughan et al., 2003). For this reason, in order to make a more realistic analysis of the responses of

101 Antarctic vascular plants to global warming, experimental studies should be performed considering their

102 current and projected site-specific temperatures.

103 The main goals of this study were to determine whether populations of C. quitensis possess latitudinal

104 variation in several traits (foliar anatomy and pigments) that avoids photoinhibition and to determine

105 whether the ecophysiological response to simulated climate change will differ among populations

106 distributed along a latitudinal gradient. We specifically addressed the following questions: (1) Does $C$.

107 quitensis show signs of clinal variation in anatomical (foliar microstructures) or physiological

108 (xanthophyll pigments) traits along a latitudinal gradient in which environmental stress (the combination

109 of cold, aridity and photo-inhibitory radiation) increases with latitude? (2) Will southern populations of $C$.

110 quitensis be more responsive to simulated global warming than more northern populations? To address

111 these questions, we measured leaf anatomy and xanthophyll pigments in C. quitensis along a latitudinal

112 gradient consisting of three locations from South America to the Antarctic Peninsula. In addition, we

113 measured the change of the photosynthetic responses, total biomass and flower production in C. quitensis

114 from all locations exposed for three years to simulated global warming.

\section{MATERIALS AND METHODS}

\section{Target species and study sites}

118 Commonly known as the Antarctic pearlwort, Colobanthus quitensis (Kunth) Bartl. (Caryophyllaceae), is 119 a small-sized cushion-like perennial herb with an extremely wide distribution range spanning from

120 Mexico $\left(17^{\circ} \mathrm{N}\right)$ to the Antarctic continent $\left(68^{\circ} \mathrm{S}\right)$; sporadic populations can be found in different islands

121 of Maritime Antarctica, as well as along the coast of the Antarctic Peninsula (Smith, 2003). C. quitensis

122 individuals in Antarctic ecosystems are mostly distributed near seashores which are frequently associated 
123 with $D$. antarctica and mosses. Clonal reproduction is the more common means of propagation in the

124 Antarctic populations of $C$. quitensis, but it is also capable of self-compatible sexual reproduction 125 (Convey, 1996).

126 Individuals of $C$. quitensis were collected from three locations along a simple latitudinal transect: 127 South America (SA), close to the city of Punta Arenas $\left(53.1^{\circ} \mathrm{S}-70.9^{\circ} \mathrm{W}\right)$; South Shetland Islands (SI), 128 close to the Polish Antarctic Station in Admiralty Bay $\left(62.1^{\circ} \mathrm{S}-58.3^{\circ} \mathrm{W}\right)$, and the Antarctic Peninsula 129 (AP), in Lagotellerie Island $\left(67.5^{\circ} \mathrm{S}-67.2^{\circ} \mathrm{W}\right.$ ) (Fig. 1). Sixty plants were dug out from each site during 130 the 2014/2015 growing season with enough soil around the roots (ca. $250 \mathrm{~g}$ ) and kept well-watered in a 131 plastic box under natural conditions of light and temperature until their transportation to the growth 132 chambers at the Universidad de Talca, Chile $\left(35.2^{\circ} \mathrm{S}\right)$. All plants were collected under permission of the 133 Chilean Antarctic Institute (INACH; authorization number: 1060/2014).

\section{Latitudinal trait variation in pigments and microstructures}

Variations in anatomical (foliar microstructure) and physiological (photoprotective pigment) traits were assessed in individuals from all locations along the latitudinal gradient. Specifically, in 25 individuals from each location (one leaf per plant) we measured and compared five microstructure foliar traits: cuticle, mesophyll, palisade parenchyma and spongy mesophyll width [mm], and leaf transversal area $\left.\left[\mathrm{mm}^{2}\right]\right)$. In the laboratory, leaves were sectioned in $2-3 \mathrm{~mm}$ in length and dehydrated in a graded ethanol series. Thin fragments of 75-100 nm sections were prepared on an ultra-microtome. Sections were stained with toluidine blue and viewed with a light microscope to analyse morphological attributes of the leaf. Thin sections were cut with a diamond knife and were stained on grids with uranyl acetate and lead citrate, and then examined in transmission electron microscope.

In addition, in a subset of 15 individuals from each location (one leaf per plant), we estimated the xanthophyll-cycle pigment content (violaxanthin, antheraxanthin and zeaxanthin) and the de-epoxidation state of the xanthophyll cycle pigments (DEPS). Leaves were repeatedly extracted (3 times) with ice-cold 
$14885 \%(\mathrm{v} / \mathrm{v})$ acetone and $100 \%$ acetone using sonication for 45 minutes at $4^{\circ} \mathrm{C}$. Pigments were separated on 149 a Dupont non-end capped Zorbax ODS-5 $\square \mathrm{m}$ column at $30^{\circ} \mathrm{C}$ at a flow rate of $1 \mathrm{ml} \mathrm{min}-1$. The solvents 150 consisted of (A) acetonitrile/methanol (85:15, v/v) and (B) methanol/ethyl acetate (68:32, v/v). The HPLC 151 gradient used was: $0-14 \min 100 \% \mathrm{~A}, 14-16$ min decreasing to $0 \% \mathrm{~A}, 16-28 \mathrm{~min} 0 \% \mathrm{~A}, 28-30 \mathrm{~min}$ 152 increasing to $100 \% \mathrm{~A}$, and $30-38 \min 100 \% \mathrm{~A}$. Detection was carried out at $445 \mathrm{~nm}$. The de-epoxidation 153 state (DEPS) of the pigments involved in the xanthophyll cycle was quantified as $\mathrm{Z}+(0.5 \times \mathrm{A}) /(\mathrm{V}+\mathrm{A}+$ 154 Z) (for more details see Molina-Montenegro et al., 2012).

\section{Latitudinal responses to simulated global warming experiment}

157 To evaluate whether different latitudinal origins of $C$. quitensis differ in the magnitude of their responses America, Shetland Islands and Antarctic Peninsula) under current and future temperature conditions (warming) predicted by climate change models (IPCC, 2014). Based on the available predictions, a $4{ }^{\circ} \mathrm{C}$ increase in temperature was applied as warming treatment for all populations. Thus, "current" temperatures were $10{ }^{\circ} \mathrm{C}, 5^{\circ} \mathrm{C}$ and $3^{\circ} \mathrm{C}$ for SA, SI and AP, and "warming" temperatures were $14{ }^{\circ} \mathrm{C}, 9^{\circ} \mathrm{C}$ and $7{ }^{\circ} \mathrm{C}$ for SA, SI and AP, respectively.

We established six experimental abiotic conditions using six automatic air-cooling growth chambers (model: LTJ300LY; Tianyi Cool, China) to simulate current and future environmental conditions during summer months of each latitudinal origin. The current conditions for each location were: South America (mean temperature: $10^{\circ} \mathrm{C}$, photoperiod: 18/6 h light/dark), Shetland Islands (mean temperature: $5^{\circ} \mathrm{C}$, photoperiod: 19/5 h light/dark) and Antarctic Peninsula (mean temperature: $3^{\circ} \mathrm{C}$, photoperiod: $21 / 3 \mathrm{~h}$ light/dark). In addition, future conditions for each location were: South America (mean temperature: $14^{\circ}$

$170 \mathrm{C}$, photoperiod: 18/6 h light/dark), Shetland Islands (mean temperature: $9^{\circ} \mathrm{C}$, photoperiod: 19/5 h 171 light/dark) and Antarctic Peninsula (mean temperature: $7^{\circ} \mathrm{C}$, photoperiod: $21 / 3 \mathrm{~h}$ light/dark). During all experimental time every chamber was maintained in the temperature and photoperiod indicated above, 
173 with a constant intensity of the photosynthetic active radiation (PAR) of $275 \mu \mathrm{mol} \mathrm{m} \mathrm{m}^{-2} \mathrm{~s}^{-1}$ But PAR was

174 lowered to $20 \mu \mathrm{mol} \mathrm{m} \mathrm{m}^{-2} \mathrm{~s}^{-1}$ during seven months in order to mimic the natural variation in the solar 175 radiation that affect at high latitude populations. A total of 30 plants per each latitudinal origin (SA, SI 176 and AP) were randomly assigned to the current or warming conditions. Hence, in each growth chamber a 177 total of 15 plants were maintained during three years, and once per year in January (middle of the 178 growing season), photosynthetic rate was recorded on every individual in both current and warming 179 conditions. The photosynthetic rate was recorded using an infra-red gas analyzer (IRGA, model Ciras-2, PP-System, USA) under the same temperature of each growth chamber. In addition, at the end of the third year two fitness-related traits were measured as response variables, total biomass accumulation and reproductive effort. Total plant growth was measured as the average individual total biomass increase 183 (final biomass - initial biomass, g) during the three years of the experiment. At the beginning of the experiments, we selected similar size plants (from each origin). These plants were randomly assigned to current and warming treatments. There were no differences in the initial weight of plants between current and warming treatments for any latitude (one-way ANOVA, $F_{2,87}=29,4 ; p<0.001$ ). At the end of the experiments, whole plants were harvested (root plus shoot), and individually weighed using a digital balance. Reproductive effort was measured by counting the number of flowers produced by each plant during the last year of the experiment. Since there were no differences in initial plant biomass (fresh weight) between current and future thermal regimes, all individuals were weighed before the start of the experiment. The magnitude of the responses of each latitudinal origin of $C$. quitensis to experimental warming was estimated as the average difference between future and current thermal conditions (i.e., delta $=$ future - current values).

\section{Statistical analysis}

We used one-way ANOVAs to assess the significance of the observed differences between origins for all 
198

199

200

201

202

203

204

205

206

207

208

209

210

211

212

213

214

215

216

217

218

219

magnitude of the responses of $C$. quitensis to experimental warming on the delta values (future - current conditions) for each trait (photosynthetic rate, total biomass accumulation, and reproductive effort) in different populations along of the latitudinal gradient was tested using one-way ANOVAs. In all analyses, significant differences between treatments were estimated using Tukey tests (HSD) as post-hoc comparisons. Due to the number of multiple comparisons the sequential Bonferroni correction was applied to all a posteriori contrasts. All statistical tests were made using R v.3.1.3 (R-Core Team, 2015).

\section{RESULTS}

Latitudinal trait variation in pigments and microstructures

As predicted, pigment contents (xanthophyll-cycle pigments), de-epoxidation state of pigments (DEPS) and micro-structural foliar traits showed a clinal pattern of variation (Table 1 and Table S1). With the exception of antheraxanthin that did not have a clear relationship with latitude, concentration of the other pigments and the DEPS significantly increased with latitude (Table 1). Leaves became significantly thicker and more cylindrical towards higher latitudes (Table 1 and Table S1). This pattern of clinal variation is consistent with the increase in the photo-inhibitory conditions (lower temperatures and moisture and longer daylight exposition) at higher latitudes.

\section{Latitudinal responses to simulated global warming experiment}

The photosynthetic rates of $C$. quitensis exposed to experimental warming were significantly different among latitudinal origins (Fig. 2A-C; Table S2, S3). The greatest response to experimental warming was found in individuals from the southernmost population (AP), while individuals from South America showed the lowest response to experimental warming (Fig. 2; Table S2, S3).

At the end of third year, experimental warming also had a greater positive and significant effect on total biomass accumulation and reproductive effort of Antarctic Peninsula C. quitensis individuals than those from South America or even from the Shetland Islands (Fig. 3; Table S2, S3), suggesting that the 
223 observed differences in the photosynthetic response are also effectively translated into important fitness-

224 related traits.

225

226 DISCUSSION

227 Our results indicate that in the widely distributed C. quitensis, morphological and physiological traits

228 reflect an asymmetric response associated with increasing environmental stress induced by a combination

229 of increasingly colder, arid and photo-inhibitory conditions with latitude. Moreover, photosynthetic

230 performance and fitness-related traits were increased with warming in all populations. The prediction that

231 responses to experimental warming would differ over latitude was supported by the greater responses in

232 photosynthesis, biomass and reproductive effort found in the southernmost population of C. quitensis.

233 Together, our findings suggest that the direction and magnitude of the responses of C. quitensis to global

234 warming will be positive and specific to latitude.

235

236

Latitudinal trait variation in pigments and microstructures

237 The prediction of a progressive latitudinal change in both physiological and morphological traits was supported by seven of the eight traits measured in $C$. quitensis. The direction of the trait variation was consistent with the functional physiological responses expected to cope with increasingly stressful abiotic conditions such as cold temperatures, low water availability and longer daylight periods found in the Antarctic continent (Alberdi et al., 2002; Convey, 2006). Despite the clear clinal variation in functional traits shown by $C$. quitensis that cope with photoinhibitory conditions, the biological performance (biomass and flower production) was lower in the southern margin. This result seems to agree with the core of the "spatial ecology theory" (Gaston, 2009; Sexton, Hangartner \& Hoffman, 2014), which states that peripheral populations reduce their biological performance as a consequence of the reductions in habitat suitability and increased isolation (see, Sagarin \& Gaines, 2002; Vaupel \& Matthies, 2012).

247 Several studies have documented that high levels of the xanthophyll cycle pool could be considered as 248 a pivotal mechanisms to avoid photoinhibition under high radiation and/or low temperature (Demmig- 
249 Adams \& Adams, 1996; García-Plazaola et al., 2007; Molina-Montenegro et al., 2012b). In addition, high

250 levels of the xanthophyll cycle pool have been correlated with thermal dissipation of excess energy, being

251 a dynamic and reversible mechanism in plants that inhabit cold environments (Bravo et al., 2007;

252 Bascuñan-Godoy et al., 2010; Molina-Montenegro et al., 2012b; Míguez et al., 2015). In our study, those

253 individuals of $C$. quitensis living in the south edge of distribution showed a significantly higher

254 xanthophyll cycle pool, suggesting that in this population the capacity to avoid photoinhibition and to

255 maintain its growth rate could be explained -at least in part- by the presence of this mechanism. The de-

256 epoxidation state was also higher in the southern populations, where environmental stress is greater. The

257 high de-epoxidation state found in all C. quitensis populations may be related to the capacity to dissipate

258 excess energy, avoiding photoinhibition; this was more evident in the southern population where a

259 combination of environmental stress conditions (colder, dryer, and photo-inhibitory) is found.

260 Morphological adaptations have been documented as one of the main mechanisms in plants to cope

261 with environments (Mooney et al., 1991; and references therein). Foliar modifications in C. quitensis

262 exposed to different abiotic conditions have been previously reported (Bascuñan-Godoy et al., 2010;

263 Cavieres et al., 2016). We found that toward higher latitudes, C. quitensis individuals showed lower leaf

264 transversal area and greater mesophyll thickness. It has been reported that increases in leaf thickness

265 under cold acclimation may be beneficial for leaf survival under frost-induced cell dehydration, reducing

266 the mechanical stress experienced during thawing (Stefanowska et al., 1999). The thicker palisade

267 parenchyma shown by the southern population is likely to be associated with the higher photosynthesis

268 values, since this foliar adaptation can influence $\mathrm{CO}_{2}$ diffusion and assimilation (Vieira \& Mantovani,

269 1995). These variations in foliar micro-structures seem to be a constitutive adaptation, since trait

270 differences between populations were partially maintained in a common garden under controlled

271 laboratory condition, suggesting that these functional adaptations could have a genetic basis.

\section{Latitudinal responses to global warming}


274 Altitudinal and latitudinal shifts in distribution are among the earlier impacts of global warming observed

275 in plants (e.g., Menzel et al., 2006; Kelly \& Goulden, 2008; Kopp et al., 2014). Nonetheless, there are still

276 few studies focusing on the potential adaptive responses of plant species to climate change (but see

277 Nicotra et al., 2010; Merilä \& Hendry, 2014). If increased temperature associated with climate change

278 exceeds the thermal tolerance of a plant species, the species may either: (1) adjust to the new

279 environmental conditions through acclimation (through phenotypic plasticity) or evolve (ecotype

280 differentiation due to natural selection) (Bellard et al., 2012), or (2) track suitable environmental

281 conditions in space (changing their geographical distribution) and/or time (adjusting their phenology and

282 physiology). In contrast, if increased temperatures do not exceed the thermal tolerance, plastic responses

283 rather than ecotype differentiation should be expected. Overall, our results indicate that C. quitensis will

284 mainly respond to future warming through plastic adjustment and probably through range shifts after local

285 scale population expansions in response to global change. However, biotic interactions (mostly

286 competitive) will be also relevant to predict how this species will deal with future climate change. In a

287 recent study, Torres-Díaz et al. (2016) showed that responses of C. quitensis to future climate change will

288 be not only modulated by abiotic factors such as temperature and soil moisture, but also by biotic

289 interactions with fungal endophytes. Moreover, plant-plant interactions between C. quitensis and the

290 native and invasive plants could be even more critical to forecast the impacts of climate change on

291 Antarctic vegetation. As shown by Molina-Montenegro et al. (2016) the alien P. annua shows high

292 adaptive plasticity and greater competitive ability than the native $D$. antarctica. Therefore future studies

293 should address how climate change will affect the interactions between the native species and also

294 between the native $C$. quitensis and the alien P. annua.

295 Although environmental stress releasing due to future warming may promote anatomical changes that

296 would increase traits such as light absorption, photosynthesis, growth and reproductive effort, warming

297 may also compromise plant freezing tolerance and photoprotection. Warming has been reported to reduce

298 the ability of perennial plants to resist freezing events through cold de-acclimation (reviewed in Pagter \&

299 Arora, 2013). Similar effects have been found in Andean plants exposed to experimental warming (e.g., 
300 Sierra-Almeida \& Cavieres, 2010). Thus, future studies should address these potentially negative effects

301 of stress releasing on Antarctic vascular plants.

302 Antarctic vascular plants are distributed along one of the most stressful gradients of the world, being

303 affected by extreme environmental pressures that often limit their individual performance and population

304 dynamics (Peck, Convey \& Barnes, 2006). Nevertheless, recent warming during the last decades has

305 already increased their frequency and distribution (Cannone et al., 2016). In a recent review, Valladares et

306 al. (2014) showed how plastic responses are highly variable between populations of the same species, and

307 how the spatial distribution of these responses are key to cope with rapid anthropogenic climate change.

308 Understanding the adaptive response landscape of both plastic and selective processes would greatly

309 improve the forecasting of the local and regional effects of global warming on plant species, particularly

310 those with widespread ranges of distribution such Antarctic vascular plants.

311 It is important to mention that future climate change will not only raise temperature but will also

312 increase liquid precipitation. For instance, Turner et al., (2009) documented increases in precipitation in

313 the Antarctic Peninsula. It is important to acknowledge that in our experimental design plants we only

314 evaluated the response of plants to warming, maintaining irrigation similar for both treatments. As shown

315 in Torres-Díaz et al., (2016) warming tend have lower effects than watering or combined warming plus

316 watering on $C$. quitensis fitness. Therefore, our experimental design might have underestimated the

317 effects of future climate change on C. quitensis net photosynthesis, growth and reproductive effort.

319 Final remarks

320 It is important to note that our study is not free of limitations. Natural environmental conditions are

321 almost impossible to reproduce in growth chambers, thus our estimations of plant performance could

322 differ from those we would find in the field. Natural conditions were not fully mimicked in our

323 experimental setup and future experimental research under field conditions could provide more accurate

324 predictions of the effects of warming on C. quitensis performance. Field experiments using open top

325 chambers (OTCs) would have been the more realistic way to study the future responses of C. quitensis to 
326 environmental warming. Nonetheless, as shown by Torres-Díaz et al. (2016) the responses of C. quitensis 327 to future climate change can be complex, modulated by abiotic and biotic interactions, and additive and 328 even antagonistic effects may affect the results of laboratory experiments.

329

330 ACKNOWLEDGEMENTS

331 We thank INACH, the Chilean Navy and the Arctowski Polish Antarctic Station for their logistical 332 support. We thank Manuel Balaguer for data sampling in the simulated global warming experiments. This

333 article contributes to the SCAR biological research programs "Antarctic Thresholds - Ecosystem 334 Resilience and Adaptation" (AnT-ERA) and "State of the Antarctic Ecosystem" (Ant-Eco). 


\section{REFERENCES}

Alberdi M, Bravo LA, Gutiérrez A, Gidekel M, Corcuera LJ. 2002. Ecophysiology of Antarctic vascular plants. Physiologia Plantarum 115(4):479-486 DOI $\quad$ 10.1034/j.13993054.2002.1150401.x.

Bascuñan-Godoy L, García-Plazaola JI, Bravo LA, Corcuera LJ. 2010. Leaf functional and micromorphological photoprotective attributes in two ecotypes of Colobanthus quitensis from the Andes and Maritime Antarctic. Polar Biology 33(7):885-896 DOI 10.1007/s00300-0100765-4.

Bellard C, Bertelsmeier C, Leadley P, Thuiller W, \& Courchamp F. 2012. Impacts of climate change on the future of biodiversity. Ecology Letters 15(4):365-377 DOI: $10.1111 / \mathrm{j} .1461$ 0248.2011.01736.x.

Bravo LA, Saavedra-Mella FA, Vera F, Guerra A, Cavieres LA, Ivanov AG, Huner NP, Corcuera LJ. 2007. Effect of cold acclimation on the photosynthetic performance of two ecotypes of Colobanthus quitensis (Kunth) Bartl. Journal of Experimental Botany 58(13):3581-3590 DOI 10.1093/xb/erm206.

Cannone N, Guglielmin M, Convey P, Worland M, Favero-Longo S. 2016. Vascular plants changes in extreme environments: effect of multiple drivers. Climatic Change 134(4):651-665 DOI 10.1007/s10584-015-1551-7.

Cavieres LA, Sáez P, Sanhueza C, Sierra-Almeida A, Rabert C, Corcuera JL, Alberdi M, Bravo LA 2016. Ecophysiological traits and adaptations of Antarctic vascular plants: their importance in the responses to climate change. Plant Ecology 217(3):343-358 DOI 10.1007/s11258-016-0585-x.

Convey P. 1996. The influence of environmental characteristics on life history attributes of Antarctic terrestrial biota. Biological Reviews 71(2):191-225 DOI 10.1111/j.1469-185X.1996.tb00747.x.

Convey P. 2006. Antarctic climate change and its influences on terrestrial ecosystems. In Bergstrom DM, Convey P, Huiskes AHL. eds. Trends in Antarctic and Limnetic Ecosystems: Antarctica as a Global Indicator, Dordrecht: Springer, 253-272. 
362

363

364

365

366

367

368

369

370

371

372

Convey P. 2011. Antarctic terrestrial biodiversity in a changing world. Polar Biology 34(11):1629-1641 DOI 10.1007/s00300-011-1068-0.

Convey P. 2012. Life in the cold: polar terrestrial. In Bell E, ed. Life at Extremes Wallingford: CABI Publishing, 81-102.

Convey P, Chown SL, Clarke A, Barnes DA, Bokhorst S, Cummings V, Ducklow HW, Frati F, Green TGA, Gordon S, Griffiths HJ, Howard-Williams C, Huiskes AHL, Laybourn-Parry, Lyons WB, McMinn A, Morley SA, Peck LS, Quesada A, Robinson SA, Schiaparelli S, Wall DH. 2014. The spatial structure of Antarctic biodiversity. Ecological Monograph 80(2):203-244 DOI 10.1890/12-2216.1.

Day TA, Ruhland CT, Grobe CW, Xiong FS. 1999. Growth and reproduction of Antarctic vascular plants in response to warming and UV radiation reductions in the field. Oecologia 119(2):24-35 DOI $10.1007 / \mathrm{s} 004420050757$.

Day TA, Ruhland CT, Strauss SL, Park JH, Krieg ML, Krna MA, Bryant DM. 2009. Response of plants and the dominant microarthropod, Cryptopygus antarcticus, to warming and contrasting precipitation regimes in Antarctic tundra. Global Change Biology 15(7):1640-1651 DOI 10.1111/j.1365-2486.2009.01919.x.

Day T, Christopher A, Ruhland T, Xiong FS. 2008. Warming increases aboveground plant biomass and C stocks in vascular-plant-dominated Antarctic tundra. Global Change Biology 14(8):18271843 DOI 10.1111/j.1365-2486.2008.01623.x.

Demmig-Adams B, Adams III W. 1992. Photoprotection and other responses of plants to high light stress. Annual Review of Plant Physiology and Plant Molecular Biology 43:599-626 10.1146/annurev.pp.43.060192.003123.

Demmig-Adams B, Adams III W. 1996. The role of xanthophyll cycle carotenoids in the protection of photosynthesis. Trends in Plant Science 1(1):21-26 DOI http://dx.doi.org/10.1016/S13601385(96)80019-7. 
387 388 389

García-Plazaola JI, Matsubara S, Osmond B. 2007. The lutein epoxide cycle in higher plants: its relationship to other xantho- phyll cycles and possible functions. Functional Plant Biology 34(9):759-773 DOI http://dx.doi.org/10.1071/FP07095.

Gaston KJ. 2009. Geographic range limits of species. Proceedings of the Royal Society of London B: Biological Sciences 276(1661):1391-1393 DOI 10.1098/rspb.2009.0100.

Gianoli E, Hinostroza P, Zúñiga-Feest A, Reyes-Díaz M, Cavieres LA, Bravo LA, Corcuera LJ. 2004. Ecotypic differentiation in morphology and cold resistance in populations of Colobanthus quitensis (Caryophyllaceae) from the Andes of central Chile and the maritime Antarctic. Arctic, Antarctic and Alpine Research 36(4):484-489 DOI http://dx.doi.org/10.1657/15230430(2004)036[0484:EDIMAC]2.0.CO;2.

Intergovernmental Panel of Climate Change (IPCC). 2014. The Physical Science Basis. Available from www.ipcc.ch

Kennedy AD. 1993. Water as a limiting factor in the Antarctic terrestrial environment: A biogeographical synthesis. Arctic and Alpine Research 25(4):308-315 DOI 10.2307/1551914.

Kopp CW, Cleland EE. 2014. Shifts in plant species elevational range limits and abundances observed over nearly five decades in a western North America mountain range. Journal of Vegetation Science 25(1): 135-146 DOI 10.1111/jvs.12072.

Menzel A, Sparks TH, Estrella N, Koch E, Aasa A, Ahas R, Alm-Kübler K. Bissolli P, Bravlavska O, Briede A, Chmielewski FM, Crepinsek Z, Curnel Y, Dahl A, Defila C, Donnelly A, Filella Y, Jatczak K, Mage F, Mestre A, Nordli O, Peñuelas J, Pirinen P, Remisová V, Scheifinger H, Striz M, Susnik A, Van Vliet AJH, Wielgolaski F, Zach S, Zust A. 2006. European phenological response to climate change matches the warming pattern. Global Change Biology 12(10):19691976 DOI 10.1111/j.1365-2486.2006.01193.x.

Merilä J, Hendry AP. 2014. Climate change, adaptation, and phenotypic plasticity: the problem and the evidence. Evolutionary Applications 7(1):1-14 DOI 10.1111/eva.12137. 
412

413

414

415

416

417

418

419

420

421

422

423

424

425

426

427

428

429

430

431

432

433

434

435

436

437

Míguez, F, Fernández-Marín B, Becerril JM, García-Plazaola JI. 2015. Activation of photoprotective winter photoinhibition in plants from different environments: a literature compilation and metaanalysis. Physiologia Plantarum 155(4): 414-423 DOI 10.1111/ppl.12329.

Molina-Montenegro MA, Torres-Díaz C, Carrasco-Urra F, González-Silvestre L, Gianoli E. $2012 a$. Plasticidad fenotípica en dos poblaciones antárticas de Colobanthus quitensis (Caryophyllaceae) bajo un escenario simulado de cambio global. Gayana Botánica 69(1):87-94 DOI 10.4067/S071766432012000100015.

Molina-Montenegro MA, Peñuelas J, Munné-Bosch S, Sardans J. 2012b. Higher plasticity in ecophysiological traits enhances the performance and invasion success of Taraxacum officinale (dandelion) in alpine environments. Biological Invasions 14(1):21-33 DOI 10.1007/s10530-0110055-2.

Molina-Montenegro MA, Galleguillos C, Oses R, Acuña-Rodríguez IA, Lavín P, Gallardo-Cerda J, Torres-Díaz C, Diez B, Pizarro GE, Atala C. 2016. Adaptive phenotypic plasticity and competitive ability deployed under a climate change scenario may promote the invasion of Poa annua in Antarctica. Biological Invasions 18(3):603-618 DOI 10.1007/s10530-015-1033-x.

Mooney HA, Winner WE, Pell EJ, Chu E. 1991. Responses of plants to multiples stresses. San Diego (CA): Academic Press Inc.

Nicotra AB, Atkin OK, Bonser SP, Davidson AM, Finnegan EJ, Mathesius U, Poot P, Purugganan MD, Richards CL, Valladares F, van Kleunen M. 2010. Plant phenotypic plasticity in a changing climate. Trends Plant Science 15(2):684-692 DOI 10.1016/j.tplants.2010.09.008.

Pagter M, Arora R. 2013. Winter survival and deacclimation of perennials under warming climate: physiological perspectives. Physiologia Plantarum 147(1):75-87 DOI 10.1111/j.13993054.2012.01650.x.

Peck LS, Convey P, Barnes DK. 2006. Environmental constraints on life histories in Antarctic ecosystems: tempos, timings and predictability. Biological Reviews 81(1):75-109 DOI 10.1017/S1464793105006871. 
Kelly AE, Goulden ML. 2008. Rapid shifts in plant distribution with recent climate change. Proceedings of the National Academy of Science of the United States of America 105(33): 11823-11826 DOI 10.1073/pnas.0802891105.

R Core Team. 2015. R: a language and environment for statistical computing. Vienna: R Foundation for Statistical Computing.

Robinson SA, Wasley J, Tobin AK. 2003. Living on the edge - plants and global change in continental and maritime Antarctica. Global Change Biology 9(12):1681-1717 DOI 10.1046/j.13652486.2003.00693.x.

Sagarin R, Gaines SD. 2002. The 'abundant centre' distribution: To what extent is it a biogeographical rule? Ecology Letters 5(1):137-147 DOI 10.1046/j.1461-0248.2002.00297.x.

Sexton JP, Hangartner SB, Hoffman AA. 2014. Genetic isolation by environment or distance: which pattern of gene flow is most common? Evolution 68(1):1-15 DOI 10.1111/evo.12258.

Sierra-Almeida A, Cavieres LA. 2010. Summer freezing resistance decreased in high-elevation plants exposed to experimental warming in the central Chilean Andes. Oecologia 163(1):267-276 DOI $10.1007 / \mathrm{s} 00442-010-1592-6$.

Sierra-Almeida A, Casanova-Katny A, Bravo LA, Corcuera LJ. Cavieres LA. 2007. Photosynthetic responses to temperature and light of Antarctic and Andean populations of Colobanthus quitensis (Caryophyllaceae). Revista Chilena de Historia Natural 80(3):335-343 DOI 10.4067/S0716078X2007000300007.

Smith RI. 1994. Vascular plants as bioindicators of regional warming in Antarctica. Oecologia 99:322328.

Smith RI. 2003 The enigma of Colobanthus quitensis and Deschampsia antarctica in Antarctica. In: Huiskes AHL, Gieskes WWC, Rozema J, Schorno RML, van der Vies SM, Wolff WJ (eds) Antarctic biology in a global context. Backhuys Publishers, Leiden, 234-239. 
462

463

464

465

466

467

468

469

470

471

472

473

474

475

476

477

478

479

480

481

482

483

484

485

486

Stefanowska M, Kuras M, Kubacka-Zebalska M, Kacperska A. 1999. Low temperature affects pattern of leaf growth and structure of cell walls in winter oilseed rape (Brassica napus L. var. oleifera L.) plants. Annals of Botany 84(3):313-319 DOI 10.1006/anbo.1999.0924.

Torres-Díaz C, Gallardo-Cerda J, Lavín P, Oses R, Carrasco-Urra F, Atala C, Acuña-Rodríguez IS, Convey P, Molina-Montenegro MA. 2016. Biological Interactions and Simulated Climate Change Modulates the Ecophysiological Performance of Colobanthus quitensis in the Antarctic Ecosystem. PLoS ONE 11(10):e0164844 DOI 10.1371/journal.pone.0164844.

Torres-Mellado G, Jaña R, Casanova-Katny MA. 2011. Antarctic hairgrass expansion in the South Shetland Archipelago and Antarctic Peninsula revisited. Polar Biology 34(11):1679-1688 DOI 10.1007/s00300-011-1099-6.

Turner, J., Bindschadler R, Convey P, Di Prisco G, Fahrbach E, Gutt J, Hodgson DA, Mayewski PA Summerhayes CP. 2009. Antarctic climate change and the environment. Cambridge: Scientific Committee for Antarctic Research, 554 pp.

Turner J, Barrand N, Bracegirdle T, Convey P, Hodgson DA, Jarvis M. Jenkins A, Marshall G, Meredith MP, Roscoe H, Shanklin J, French J, Goose H, Guglielmin M, Gutt J, Jacobs S, Kennicut MC, Masson-delmonte V, Mayewski P, Navarro F, Robinson S, Scambos T, Sparrow M, Summerhayes C, Speer K, Klepikov A. 2014. Antarctic climate change and the environment: an update. Polar Record 50(3):237-259 DOI 10.1017/S0032247413000296.

Turner J, Ku H, White I, King JC, Phillips J, Hosking JS, Bracegirdle TJ, Marshall GJ, Mulvaney R, Pranab D. 2016. Absence of 21 st century warming on Antarctic Peninsula consistent with natural variability. Nature 535(7612):411-415 DOI 10.1038/nature18645.

Valladares F, Matesanz S, Guilhaumon F, Araújo MB, Balaguer L, Benito-Garzón M, Cornwell W, Gianoli E, van Kleunen M, Naya DE, Nicotra AB, Poorter H, Zavala MA. 2014. The effects of phenotypic plasticity and local adaptation on forecasts of species range shifts under climate change. Ecology Letters 17(119:1351-1364 DOI 10.111/ele.12348. 
Vaughan DG, Marshall GJ, Connolley, WM, Parkinson, C, Mulvaney R, Hodgson DA, King JC, Pudsey CJ, Turner J. 2003. Recent rapid regional climate warming on the Antarctic Peninsula. Climate Change 60(3):243-274 DOI 10.1023/A:1026021217991.

Vaupel A, Matthies D. 2012. Abundance, reproduction, and seed predation of an alpine plant decrease from the center toward the range limit. Ecology 93(10):2253-2262 DOI 10.1890/11-2026.1.

Vieira R, Mantovani A. 1995. Anatomía foliar de Deschampsia antarctica Desv. (Gramineae). Revista Brasileira de Botanica 18(2):207-220.

Walther GR, Post E, Convey P, Menzel A, Parmesan C, Beebee TJC, Fromentin JM, HoeghGuldberg O, Bairlein F. 2002. Ecological responses to recent climate change. Nature 416(6879):389-395 DOI 10.1038/416389a.

Wasley J, Robinson SA, Lovelock CE, Popp M. 2006. Climate change manipulations show Antarctic flora is more strongly affected by elevated nutrients than water. Global Change Biology 12(9):18001812 DOI 10.1111/j.1365-2486.2006.01209.x. 


\section{$501 \quad$ Figure legend}

502 Figure 1. Sites where individuals of Colobanthus quitensis were collected: (A) South America (SA:

$50353.5^{\circ} \mathrm{S}$ ), (B) Shetland Islands (SI: $62.1^{\circ} \mathrm{S}$ ) and (C) Antarctic Peninsula (AP: $67.5^{\circ} \mathrm{S}$ ). Locations

504 photographed by Marco A. Molina-Montenegro on 2012-2013 growing season.

505 Figure 2: Frequency distribution of the photosynthetic response of Colobanthus quitensis individuals 506 from three different origins (South America 53.5 $\mathrm{S}$, Shetland Islands $62.1^{\circ} \mathrm{S}$ and Antarctic Peninsula $50767.5^{\circ} \mathrm{S}$ ). Estimations were performed under both the current thermal conditions of each site $\left(\mathrm{t}_{0}\right)$, and 508 during three consecutive simulated growing seasons $\left(t_{1}: t_{3}\right)$, where all individuals experienced their 509 respective projected temperatures. The extent of the mean temporal response for each population is 510 expressed as the mean delta value $( \pm \mathrm{SD})$ between the photosynthetic responses at the last simulated 511 warming season $\left(\mathrm{t}_{3}\right)$ and their values under the current thermal conditions $\left(\mathrm{t}_{0}\right)$. Different letters between 512 these values refer to significant differences (Tukey HSD tests, $\alpha=0.05$ ) between populations. Bonferroni 513 correction was applied due to multiple comparisons.

514 Figure 3: Violin plot for the average response of Colobanthus quitensis from three different latitudinal 515 origins: South America (SA: $\left.53.5^{\circ} \mathrm{S}\right)$, Shetland Islands (SI: $\left.62.1^{\circ} \mathrm{S}\right)$ and Antarctic Peninsula (AP: $\left.67.5^{\circ} \mathrm{S}\right)$ 516 to experimental warming. The effects of warming $\left(+4^{\circ} \mathrm{C}\right)$ were estimated as the absolute difference (i.e., 517 delta) between plant performance under warming (simulated future conditions) and current thermal 518 conditions in two fitness-related traits: aboveground biomass accumulation delta in grams (A) and 519 reproductive effort delta estimated as the number of produced flowers (B). The mean delta value for each 520 population in both traits was obtained after averaging the mean differences of each individual against all 521 other plants from the same population. The box and whisker plot inside the violins represent the 522 interquartile distribution of the data around the median (box inner line). Black dots correspond to outlier 523 values. Different letters indicate significant differences (Tukey HSD tests, a $=0.05$ ) between populations. 


\section{Figure 1}
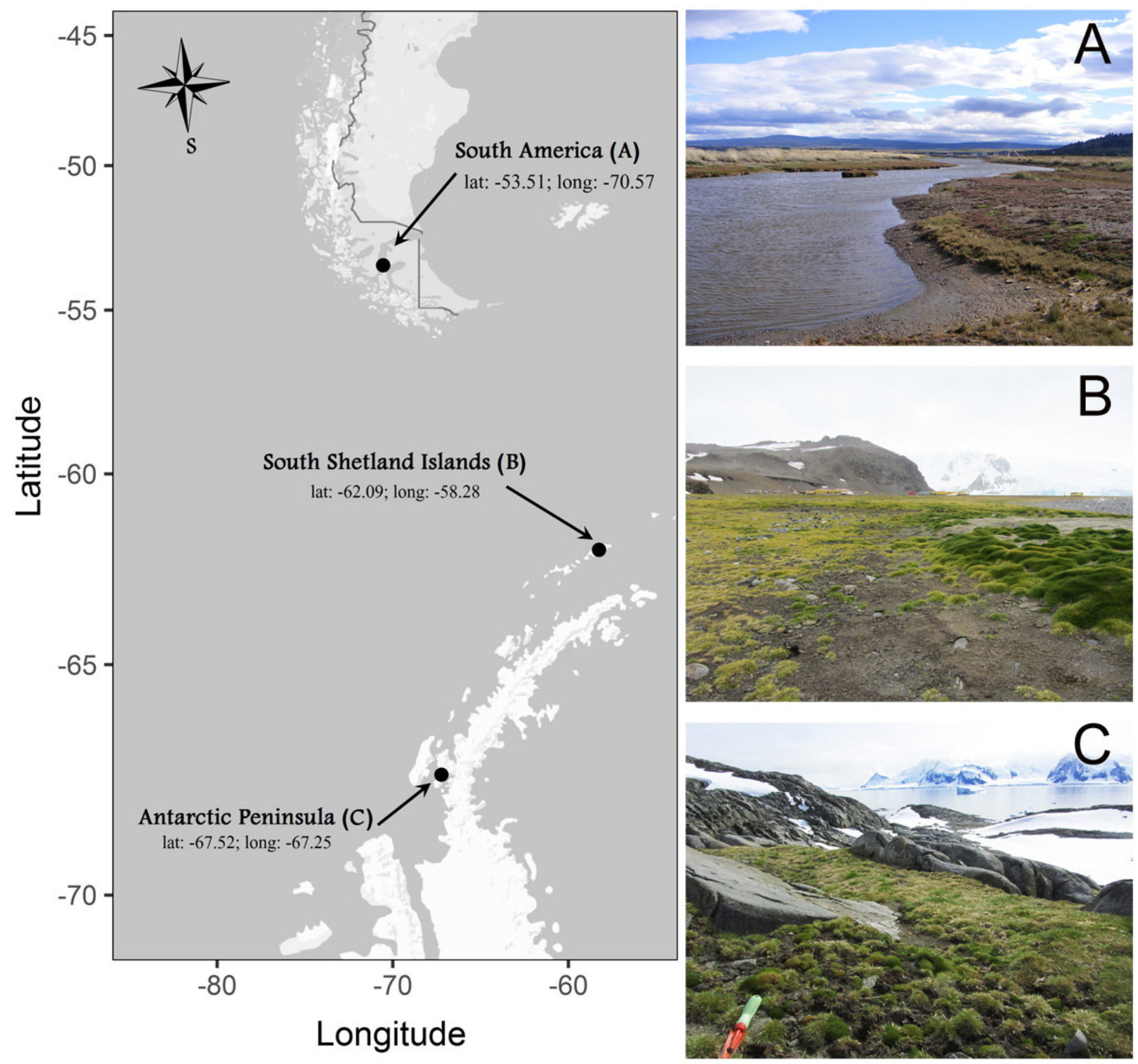

528 
532

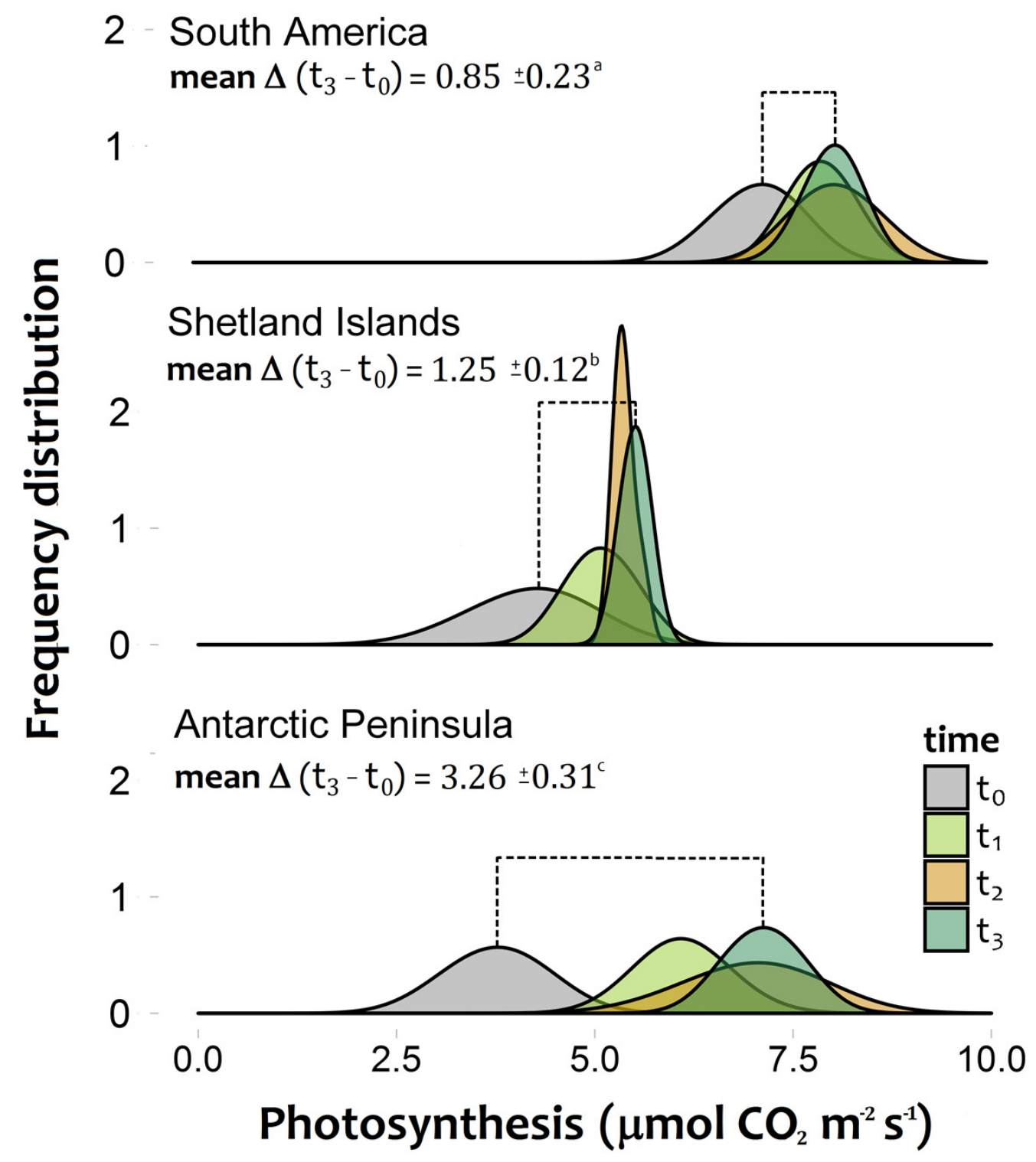


Figure 3
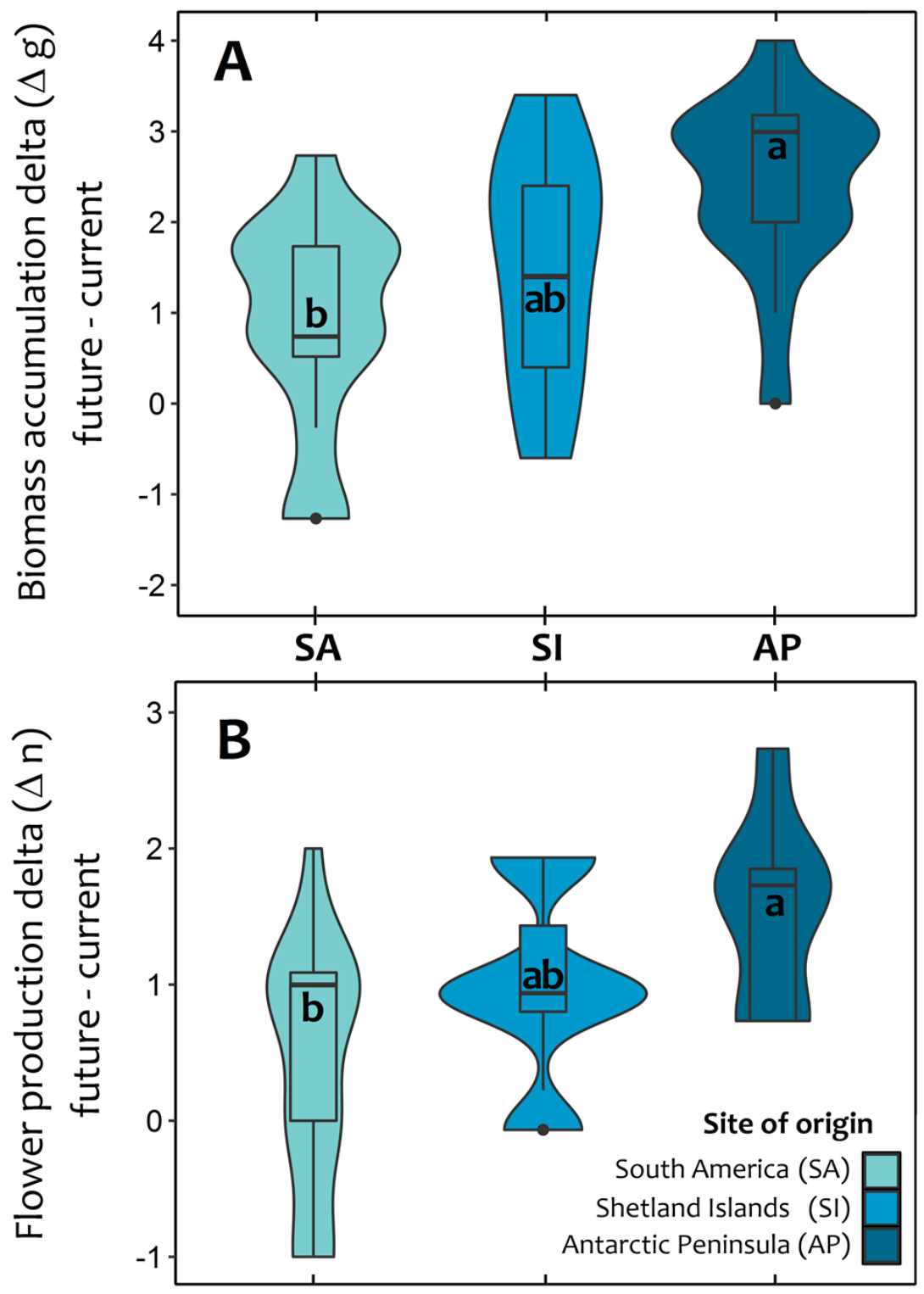